\title{
La biopsia del ganglio centinela es un método confiable de estadificación axilar del cáncer de mama
}

\section{Objetivo}

Evaluar la exactitud ${ }^{*}$ de la biopsia del ganglio centinela en la predicción del estado histológico de la axila en el cáncer de mama.

\section{Diseño}

Estudio aleatorizado controlado.

\section{Lugar}

Instituto Europeo de Oncología de Milán, Italia.

\section{Pacientes}

Mujeres de 40 a 75 años con cáncer de mama $\leq 2 \mathrm{~cm}$. Se excluyeron aquellas con cáncer multicéntrico y las que tenían una biopsia escisional previa del tumor.

\section{Intervención}

Se aleatorizaron las pacientes a dos grupos: en el Grupo Disección Axilar (GDA) se realizaba una resección local amplia y biopsia de ganglio centinela seguido de vaciamiento axilar completo; y el Grupo Ganglio Centinela (GGC) a una resección local amplia y biopsia de ganglio centinela seguida de vaciamiento axilar completo solo si el ganglio centinela contenía, en la congelación, metástasis del cáncer de mama.

\section{Medición de resultados principales}

Se evaluó la exactitud ${ }^{*}$ del ganglio centinela en el estado histológico de la axila, el valor predictivo negativo* (VPN) y en el GDA la Tasa de Falsos Negativos* (TFN: proporción de pacientes con centinela negativo pero con $\geq 1$ ganglio positivo del vaciamiento axilar). Secundariamente se evaluó calidad de vida, el número de metástasis axilares aparecidas durante el seguimiento en el GGC con centinela negativo y la sobrevida global y libre de enfermedad.

\section{Resultados principales}

Se incluyeron 532 pacientes (516 evaluables): 257 en el GDA y 259 en el GGC. En el GDA hallaron ganglio centinela en el $32 \%$ (IC95\% 27 a 38\%). En 8/174 pacientes con ganglio centinela negativo se hallaron metástasis en los ganglios del vaciamiento axilar. (TFN 4,6\%; IC95\% 2,0 a 8,9\%). La exactitud del centinela fue $96,9 \%$; el VPN $95,4 \%$ (IC95\% 91,1 a $98,0 \%$ ) y la TFN fue $8,8 \%$ (8/91 pacientes con ganglios + no se identificaron por el ganglio centinela).EI GGC tuvo menos dolor, entumecimiento y linfedema, y mayor movilidad del brazo que el GDA.

\section{Conclusión}

La biopsia del ganglio centinela es un método seguro y exacto de rastreo de metástasis en ganglios axilares en mujeres con cáncer de mama pequeños.

\section{Comentario}

La investigación del ganglio centinela se fundamenta en la teoría de que un tumor maligno de la mama se disemina por vía linfática en forma escalonada, y su primera estación es uno o más ganglios habitualmente localizados en la axila. Por medio de colorantes vitales (azul patente) ó radionucleidos inyectados en forma peritumoral o subdérmica se logra simular la ruta de migración linfática e identificar el o los ganglios centinela, cuyo estado histológico sería un indicador del resto de la axila. Hasta la fecha hay más de 8.000 pacientes incluidas en diferentes publicaciones y los resultados muestran, casi invariablemente, que constituye un método altamente confiable en la estadificación de la axila.

Este trabajo muestra una seria falla metodológica, dado que para evaluar el objetivo principal (poder predictivo del ganglio centinela) hubiera sido suficiente solo el GDA: es decir que la aleatorización fue inconducente para lograr este objetivo. Interpreto que con este diseño los autores intentaron, inicialmente, detectar diferencias en sobrevida entre uno y otro tratamiento (imposible con este número de casos) y por otro lado evaluar los efectos adversos de una simple biopsia ganglionar en relación a un vaciamiento axilar completo (motilidad, dolor, linfedema del brazo, etc.).

Es importante destacar que el método de investigación del ganglio centinela es muy seguro, principalmente porque la gran mayoría de las pacientes con tumores $<2 \mathrm{~cm}$ tienen habitualmente axila histológicamente negativa (70\%) motivo por el cual es obvio que el ganglio centinela también lo será.

Por ello el VPN y la confiabilidad del método son tan elevados. Creo que el mejor indicador del valor del método ganglio centinela es la TFN, (centinela - con axila +) es decir conocer cuántas pacientes con axila + no fueron detectadas por el centinela.

En la presente publicación la TFN fue $8.8 \%(8 / 91)$, pero esta tasa oscila entre 5 y $15 \%$ de acuerdo a diferentes autores. ${ }^{1-4}$

Sería importante conocer el significado clínico (sobrevida, recidiva axilar) de dejar ganglios axilares comprometidos sin extirpar. Para dilucidar este problema habrá que aguardar los resultados de dos estudios multicéntricos aleatorizados especialmente diseñados para tal fin: el NSABP B32 (vaciamiento axilar vs biopsia de ganglio centinela) 5 y el ACOSOG Z0011 (vaciamiento axilar con centinela + vs observación) $)^{6}$.

\section{Conclusión del comentador}

Dada la evidencia actual, la investigación del ganglio centinela es el procedimiento de elección en la estadificación de la axila en tumores pequeños, evitando el vaciamiento axilar sólo si éste es histológicamente negativo. Se requiere que el equipo médico tratante haya convalidado, en su serie de casos (no inferior a 30), la eficacia del método en relación al vaciamiento axilar.

\section{Dr. Claudio Lorusso [ Servicio de Ginecología. Hospital Italiano de Buenos Aires. ]}

Lorusso C. La biopsia del ganglio centinela es un método confiable de estatificación axilar del cáncer de mama. Evid actual pract ambul 2005:8:41. Comentado de: Veronesi U, Paganelli G, Viale G y col. A Randomized Comparison of Sentinel-Node Biopsy with Routine Axillary Dissection in Breast Cancer. N. Engl. J. Med. 2003; 349:546-53. PMID: 12904519

\section{Referencias}

1. Giuliano AE, Kirgan DM, Guenther JM, Morton DL. Lymphatic mapping and sentinel lymphadenectomy for breast cancer. Ann Surg 1994;220:391-401.

2. Krag D, Weaver D, Ashikaga T, et al. The sentinel node in breast cancer -- a multicenter validation study. N Engl J Med 1998;339:941-946.

3. Veronesi U, Paganelli G, Galimberti V, et al. Sentinel-node biopsy to avoid axillary dissection in breast cancer with clinically negative lymph-nodes. Lancet 1997;349:1864-1867.

4. Veronesi U, Paganelli G, Viale G, et al. Sentinel lymph node biopsy and axillary dissection in breast cancer: results in a large series. J Natl Cancer Inst 1999;91:368-373.

5. Krag DN, Julian T. Expert perspectives: update on NSABP-32, a randomized phase III clinical trial to compare sentinel node resection to conventional axillary dissection for clinically node-negative breast cancer. Breast Dis Year Book Q 2002;13:113-4.

6. Breast study announcements. Durham, N.C.: American College of Surgeons Oncology Group, 2003. (Accessed July 18, 2003, at http://www.acosog.org/studies/organ_site/breast/.) 